\title{
Mental health and access to care among refugee mothers relocated to San Diego: a comparative study of Iraqi and Somali refugee communities
}

\author{
William Jude Bruno ${ }^{1 * \dagger}$ (D) Kathryn Ries Tringale ${ }^{2+}$ and Wael K. Al-Delaimy ${ }^{3}$
}

\begin{abstract}
Background: Mental illness is common amongst refugees and can differ depending on cultural background, experiences, and access to care. Given significant risk factors including high rates of exposure to sexual violence and different barriers to seeking adequate health care, refugee mothers are uniquely at risk.

Methods: In 2012-2013, surveys were administered to a convenience sample of Somali and systematic random sample of Iraqi refugee mothers to identify differences in mental health between the populations. The Hopkins Symptom Checklist (HSCL-25) identified respondents with major depression and emotional distress. We used multivariable logistic regression to compare these populations and identify variables associated with mental illness.

Results: 198 Somali and 219 Iraqi women were included. Most Iraqis (60.27\%) had not seen a mental health provider while most Somalis (62.63\%) had. On average, Iraqis scored 0.34 points higher (worse) on the HSCL-25 compared to Somalis $(95 \% \mathrm{Cl}, 0.22-0.46 ; P<0.001)$. Iraqis were more likely to have major depression $(\mathrm{OR}=2.62$, $95 \% \mathrm{Cl} 1.50-4.57, P=0.001)$. On multivariable analysis accounting for the country of origin, those who saw a mental health provider were less likely to have major depression or emotional distress (OR $0.42,95 \% \mathrm{Cl} 0.22-0.82$, $P$ $=0.011 ;$ OR $0.43,95 \% \mathrm{Cl} 0.22-0.85, P=0.015$, respectively).

Discussion: Iraqi refugee mothers were more likely to have depression compared to Somalis. Refugee mothers who saw a mental health provider were less likely to have depression or emotional distress. These results suggest the cultural background and access to health services among refugee mothers' impact on mental health.
\end{abstract}

Keywords: Refugee mothers, Mental health, Depression, Relocation, Iraqi, Somali

\section{Introduction}

Refugees are at high risk of mental illness; thus, both the United Nations High Commissioner for Refugees have recognized mental health services as imperative for relocated refugees (UNHCR Mental Health 2018; WHO

\footnotetext{
* Correspondence: williamjbruno87@gmail.com

+William Jude Bruno and Kathryn Ries Tringale contributed equally to this work.

'Department of Emergency Medicine, Keck School of Medicine, University of Southern California, 1200 N State Street, Room 1011, Los Angeles, CA 90033, USA

Full list of author information is available at the end of the article
}

2012). Refugees typically follow a predictive pattern of being internally displaced, then externally displaced in a refugee camp or an asylum country before being resettled in their new adopted countries (UNHCR Global Trends 2016). This process can take years or even decades, with many refugees stuck in the transition countries for the majority of their lives (UNHCR Resettlement 2018). War, persecution, and political strife are some of the many environmental factors resulting in a disproportionately high exposure of refugees to trauma. Refugee mothers, in particular, have unique risk factors for mental illness, including high rates of 
exposure to sexual violence (Kirmayer et al. 2011). Women also have unique barriers to seeking adequate care for mental illness, previously shown to include poor language proficiency, reluctance to disclose emotional distress outside the family, unwillingness to partake in medical treatment, and fear of shame or losing one's children to authorities (Dennis and Chung-Lee 2006; Takeuchi et al. 2007). Even after they are resettled in their adopted country, this trauma continues to inflict damage on their mental well-being (Fazel et al. 2005). Furthermore, many of the places of resettlement lack sufficient, culturally appropriate mental health care capable of accommodating the special needs of resettled refugees (Silove et al. 2017).

San Diego, California, has been a resettlement hub for refugees arriving in the USA dating back to the arrival of Vietnamese evacuees fleeing the Fall of Saigon in 1975 (Matsuoka 1993). Since then, several non-profit refugee organizations operating in San Diego have helped diverse groups of refugees and asylum-seekers from around the world establish new homes. Prominent amongst these groups in terms of population size are the Somali and Iraqi refugees.

Precipitated by civil war starting in 1991, waves of Somalis fled across the border into Dadaab, Kenya (Chkam 2016). As of 2018, 235,269 inhabitants remain in the camp (UNHCR Kenya Dadaab Refugee Complex 2018), exposed to rampant overcrowding, high mortality, and malnutrition (Polonsky et al. 2013). Similar to other refugee populations, the Somali diaspora-both in the Dadaab refugee camp and those relocated-disproportionately experience mental health problems such as post-traumatic stress disorder (PTSD), depression, and suicidality (Bhui et al. 2003; Jaranson et al. 2004; Porter and Haslam 2005). About 150,000 Somalis currently live in the USA, a large portion of whom have been resettled in California (Leone 1983; UNHCR Global Trends 2016) with San Diego as a major hub. Language and cultural barriers make it difficult for Somali mothers to access sorely needed social services such as food stamps, where applications can be rejected if not filled out correctly. Officials with Somali Family Service-a refugee assistance organization in San Diego-explain that lack of access to computers and Internet make accessing these services particularly challenging (Lopez-Villafana 2020).

Following the 2003 US invasion of Iraq, fleeing Iraqis became one of the fastest growing refugee groups in the USA (Refugee Processing Center 2020). California (and San Diego in particular) has been an epicenter of Iraqi resettlement, with over 33,000 Iraqis relocating to the state between 1983 and 2017 (Leone 1983; Terrazas 2009). Similar to their Somali counterparts, Iraqis experienced a high rate of mental illness in post-invasion Iraq (Al-Nuaimi et al. 2015). Even after resettlement in the USA, Iraqi refugees continue to face disproportionately high levels of mental illness (Jamil et al. 2007; Rometsch-Ogioun El Sount et al. 2018). Iraqi refugee mothers have been studied as a particularly vulnerable population. For instance, a qualitative study of relocated Iraqi mothers highlighted some of the unique challenges this population faces (Hess et al. 2018). One respondent discussed her ambivalence regarding the decision to continue to wear the traditional head scarf, as she perceived it as attracting bigotry.

Though the circumstances that have compelled the Iraqi and Somali refugees to resettle in San Diego are quite distinct, they now find themselves in a similar geographic location with, ostensibly, similar access to mental health services. Delivering such care is challenging, particularly in an area like San Diego, which has a population of refugees from diverse cultural backgrounds. Each ethnic group presents with unique pre-flight trauma and relocation experiences, which can be difficult for the mental health practitioner to navigate (Murray et al. 2010). Compared to other groups, stigmatization and lack of cultural competencies amongst providers are higher within relocated refugee communities and result in significant barriers to care making it that much more difficult for refugees to access desperately needed resources (Murray et al. 2010).

Mothers in refugee communities are the center of families and take the burden of mental stress during displacement, rendering them particularly high risk of mental illness after resettlement (East et al. 2018; Steward et al. 2008). This study aims to better understand what factors-including demographics, health care access, perceptions of mental health-influence mental health symptoms in these two populations of resettled refugee mothers in San Diego.

\section{Methods \\ Study design}

A cross-sectional study was conducted among resettled Somali and Iraqi refugees in San Diego to collect demographic information, perceptions of mental health, mental health status, and access to health care services. The study was approved by the University of California San Diego Human Research Protections Program.

\section{Participants}

Eligible participants had to be Somali or Iraqi women who had spent time in a refugee camp. The participants had to be mothers of at least one child 7-14 years of age for Somali participants and 7-13 years of age for Iraqi participants. The age range of the children was determined to be acceptable for the purposes of administering surveys to the children on child trauma and mental illness for the purposes of a separate study (East et al. 2018). The difference in the upper age limit for the two 
groups was driven by the sample size and population interviewed, as each survey administration was done by distinct interviewers from the respective communities. Each participant was provided an incentive of a $\$ 30$ gift card for their time participating in the study.

\section{Somali participant recruitment}

In 2013, three female bilingual Somali community workers with cultural understanding of this population went door-to-door in the City Heights neighborhood of San Diego to recruit a convenience sample of Somali women refugees. The location was chosen given its high concentration of Somali residents.

\section{Iraqi participant recruitment}

Resettled Iraqis refugees are registered by their sponsoring organizations with the San Diego Department of Public Health for screening and follow-up during early resettlement. In 2012, a list of all resettled Iraqi refugees who had arrived in San Diego County within 4 years prior to the time of the survey and who had at least one child aged 7-13 was de-identified and provided to researchers by Catholic Charities in San Diego (CCSD), one of the local refugee sponsoring organizations. Out of an estimated 1000 pairs who qualify in the database kept by the CCSD, a sample of 500 mothers were randomly selected with an aim of recruiting 300 of them. CCSD followed-up the selected names through a local government agency who contacted potential participants to request permission to forward their contact information to researchers. Those refugees who gave permission were contacted via telephone by our team of Arabic speaking community interviewers who explained the study and invited them to participate. Those who refused were replaced by the next on the list of randomly selected mothers.

\section{Survey administration Somali participants}

The study interview took place in the participant's home or in a nearby private area depending on the participant's preference. A bilingual, bicultural Somali female community worker who was trained in questionnaire administration read the questionnaires to the participants. All participants' responses were entered onto a secure digital platform and exported using a passwordprotected server.

\section{Iraqi participants}

A face-to-face interview was scheduled and conducted at the International Rescue Committee office in San Diego near El Cajon where most refugees lived. All surveys were conducted via in-person interview after proper written consent.
All questions for both the Somali and Iraqi questionnaires were tested prior to conducting the study to ensure their acceptability for the study population. This process was accomplished by having the questions translated into the respective language by a bilingual member of the research team and then back-translated by a different bilingual member of the research team. We then piloted each of these surveys among family and friends of the research team who were either Somali or Iraqi.

For both groups, during the consent process, the study was explained as an investigation into the communities' health and healthcare. There was no specific mention of the study being related specifically to mental health. The surveys were administered via interview because there were several questions in the surveys that needed careful consideration, and there was concern that they may not be understood if they were self-administered. All subjects provided informed, written consent prior to participation.

\section{Independent variables}

Demographic variables, including refugee group, in addition to resettlement (i.e., length of time and number of locations resettled prior to the USA), health care access, and social/financial status variables were collected from interview data through the questionnaires. These surveys included questions on respondents' perceptions of mental health care. To define whether a respondent had stigma against mental health care, a binary variable was later created based on whether they had answered both (1) "no" to whether they had seen a mental health care provider when they needed to, and (2) the reason for it being: "I was afraid my family would know about it" or "I was afraid my friends, and larger community here would know about it."

\section{Primary outcome variable}

The Hopkins Symptom Checklist (HSCL-25) is a widely used mental health screening tool and was implemented here to measure symptoms of anxiety and depression (Derogatis et al. 1974). The instrument consists of 25 items and is divided into two parts: Part I has 10 questions to screen for anxiety, and Part II has 15 questions to screen for depression. From these responses, the "total score" is calculated as an average of all 25 items, while the "depression score" is calculated as the average of items in Part II. The total score has been previously shown to highly correlate with severe emotional distress while depression score has been shown to correlate with a diagnosis of major depression as defined by the Diagnostic and Statistical Manual of the American Psychiatric Association, IV Version (DSM-IV) (Derogatis et al. 1974). We also determined the proportion of respondents considered emotionally distressed or majorly 
depressed based on an individual's average total score $>$ 1.75 or depression score $>1.45$, respectively (Syed et al. 2008). The standard cutoffs were used for this study for ease of interpretation, consistency with prior work, and standardization between the two populations. The total score was the primary outcome for this analysis given it has been consistently shown to be highly correlated with severe emotional distress of unspecified diagnosis. Prior work has shown that the HSCL-25 can be useful in detecting those who suffer mental illness among nonwestern refugee populations (Wind et al. 2017).

\section{Statistical methods}

Analyses were performed using SPSS v24 (IBM Corp). Variables on demographics, resettlement, health care access, and perceptions of mental health for the two refugee groups were compared with descriptive statistics, including independent samples $t$ tests, Pearson chisquared tests, and one-way ANOVA with Levene's test for equality of variances. Mean differences in mental health symptoms (based on the HSCL-25 scores described above) were used as an initial comparison between the two groups. Multivariable logistic regressions (including demographic, resettlement, and health care access variables significant at $P<0.05$ on univariable analysis) were performed with the primary outcomes of depression and emotional distress. Statistical significance was set at $\alpha=0.05$ for two-tailed tests.

\section{Results}

\section{Study population}

In the final analyses, 198 Somali and 219 Iraqi women were included. Respondents who did not have complete surveys for the variables of interest were excluded. Between the two groups, there were no significant differences in age or marital status, but Iraqi respondents were more educated than Somali respondents (Table 1). On average, Somalis had a longer time awaiting resettlement in the USA compared to Iraqis (mean 6.84 years vs 2.37 years), while more Iraqi refugees went to two or more locations prior to resettlement in the USA $(9.17 \%$ vs $5.56 \%$ ). Overall, the Somali respondents felt they had improved social and financial status in the USA compared to their prior country of origin, although both populations had a small proportion of respondents who felt they could meet their financial needs "very well" (< $1 \%$ of Iraqis and $6 \%$ of Somalis). Of note, time in resettlement in the USA is not reported here given the relatively high rate of missing data amongst these variables $\left(n_{\text {missing }}=124,29.74 \%\right)$.

Health care access and perceptions of mental health care Most Iraqi and Somali respondents had a regular health care provider $(91.32 \%$ and $88.89 \%$, respectively); however, Iraqis more commonly utilized community or public centers $(76.71 \%)$ while Somalis utilized private clinics or doctor's offices (81.82\%; Table 2). Most Iraqis $(60.27 \%)$ answered that they did not see a mental health provider in the last 12 months because they felt like they "did not need to," while most Somalis (62.63\%) answered that they actually saw a mental health provider when they needed to. Fewer Somalis had stigma against mental health care compared to Iraqis $(2.63 \%$ vs $17.02 \%$, respectively). The differences in how Iraqi and Somali respondents view their health care providers in the US are shown in Additional file 1: Table S1. Responses to every variable were significantly different between the two groups. Of the respondents who reported seeing a mental health provider, most Iraqis felt like their provider listened (74.4\%) as opposed to Somalis (24.5\%). Interestingly, $82 \%$ of Somalis preferred their physician share their race compared to only $20 \%$ of Iraqis who said they preferred their own race for a physician.

\section{Mental health symptoms in the Iraqi and Somali refugee populations}

On every measurement, Iraqi respondents had worse mental health symptoms compared to Somali respondents (Table 3). Specifically, Iraqi respondents scored 0.34 points higher on average on the HSCL-25 compared to Somali respondents (95\% CI, 0.22-0.46; $P<$ 0.001 ). A significantly greater proportion of Iraqi compared to Somali respondents had emotional distress (34.56\% vs $19.19 \% ; P<0.001)$ and major depression (60.83\% vs $26.77 \% ; P<0.001)$.

On multivariable logistic regression (Table 4), Iraqi respondents were more likely to be depressed compared to Somalis (OR 2.62, 95\% CI 1.50-4.57, $P=0.001$ ), but were not significantly more likely be emotionally distressed. Those who answered that they saw a mental health provider in the USA were significantly less likely to have major depression and/or emotional distress (OR $0.42,95 \%$ CI $0.22-0.82, P=0.011$; OR $0.43,95 \%$ CI $0.22-0.85, P=0.015$, respectively). Respondents who felt they did not need to see a mental health provider were also less likely to be emotionally distressed (OR 0.47, 95\% CI $0.26-0.87, P=0.016$ ). Respondents with a prior psychiatric diagnosis were significantly more likely to have either major depression (OR 10.97, 95\% CI 3.80$31.71, P<0.001$ ) or emotional distress (OR 6.46, 95\% CI $2.87-14.58, P<0.001)$. Although time awaiting resettlement and time resettled in the USA were significant univariable predictors for both depression and emotional distress, they were not included on multivariable analyses given the relatively high rate of missing data $\left(n_{\text {miss- }}\right.$ ing $=297,71.22 \%$ and $n_{\text {missing }}=124,29.74 \%$, 
Table 1 Characteristics of the study participants

\begin{tabular}{|c|c|c|c|}
\hline & Iraqi $(N=219)$ & Somali $(N=198)$ & $P$ value \\
\hline \multicolumn{4}{|l|}{ Demographics } \\
\hline Age, years (mean $[S D]$ ) & $39.32(8.45)$ & $37.94(5.84)$ & 0.069 \\
\hline \multicolumn{4}{|l|}{ Marital status, $N(\%)$} \\
\hline $\begin{array}{l}\text { Married } \\
\text { Divorced } \\
\text { Separated } \\
\text { Widowed }\end{array}$ & $\begin{array}{l}206(94.06) \\
2(0.91) \\
10(4.57) \\
1(0.46)\end{array}$ & $\begin{array}{l}185(94.39) \\
8(4.04) \\
3(1.52) \\
0(0.00)\end{array}$ & 0.888 \\
\hline \multicolumn{4}{|l|}{ Language spoken most often } \\
\hline $\begin{array}{l}\text { Somali } \\
\text { Arabic } \\
\text { Chaldean } \\
\text { English } \\
\text { Other }\end{array}$ & $\begin{array}{l}0(0.00) \\
74(33.79) \\
139(63.47) \\
0(0.00) \\
5(2.28)\end{array}$ & $\begin{array}{l}186(93.94) \\
0(0.00) \\
0(0.00) \\
3(1.52) \\
7(3.54)\end{array}$ & - \\
\hline \multicolumn{4}{|l|}{ Religion } \\
\hline $\begin{array}{l}\text { Muslim } \\
\text { Catholic } \\
\text { Other }\end{array}$ & $\begin{array}{l}32(14.61) \\
178(81.28) \\
9(4.11)\end{array}$ & $\begin{array}{l}197(99.49) \\
0(0.00) \\
1(0.51)\end{array}$ & - \\
\hline \multicolumn{4}{|l|}{ Educational level } \\
\hline $\begin{array}{l}\text { No schooling/Elementary school } \\
\text { Middle school or above }\end{array}$ & $\begin{array}{l}37(16.89) \\
182(83.11)\end{array}$ & $\begin{array}{l}83(41.92) \\
115(58.08)\end{array}$ & $<0.001$ \\
\hline \multicolumn{4}{|l|}{ Resettlement characteristics } \\
\hline Time prior to Resettlement, years (mean [SD]) & $2.37(2.75)$ & $6.84(5.94)$ & $<0.001$ \\
\hline \multicolumn{4}{|l|}{ Number of relocations } \\
\hline $\begin{array}{l}0 \text { (directly to US) } \\
1 \text { (directly from refugee camp) } \\
2+\end{array}$ & $\begin{array}{l}17(7.80) \\
181(83.03) \\
20(9.17)\end{array}$ & $\begin{array}{l}6(3.03) \\
182(91.92) \\
11(5.56)\end{array}$ & 0.030 \\
\hline Years in the USA & $3.21(1.50)$ & $13.72(5.62)$ & $<0.001$ \\
\hline \multicolumn{4}{|l|}{ Perception of social and financial status } \\
\hline Change in social status from country of origin to USA (mean [SD]) ${ }^{a}$ & $0.33(3.81)$ & $3.53(1.76)$ & $<0.001^{\mathrm{b}}$ \\
\hline \multicolumn{4}{|l|}{ Financial status change } \\
\hline $\begin{array}{l}\text { Better } \\
\text { About the same } \\
\text { Worse }\end{array}$ & $\begin{array}{l}43(19.63) \\
41(18.72) \\
135(61.64)\end{array}$ & $\begin{array}{l}72(36.36) \\
61(30.81) \\
65(32.83)\end{array}$ & $<0.001$ \\
\hline \multicolumn{4}{|l|}{ Ability to meet financial needs } \\
\hline $\begin{array}{l}\text { Very well } \\
\text { Fairly well } \\
\text { Poorly }\end{array}$ & $\begin{array}{l}2(0.91) \\
110(50.23) \\
107(48.86)\end{array}$ & $\begin{array}{l}12(6.06) \\
96(48.48) \\
90(45.45)\end{array}$ & 0.014 \\
\hline
\end{tabular}

a'Mean number of steps up the "social ladder"

${ }^{b}$ Difference in pooled paired samples between the groups is $-1.85(95 \% \mathrm{Cl}-2.18$ to -1.52$)$

respectively) that would introduce instability into the multivariable model.

\section{Discussion}

In this cross-sectional study of refugee mothers relocated to San Diego, we found that Iraqi refugees were significantly more likely to have major depression, less likely to seek a mental health care provider, and more likely to suffer stigma of mental illness compared to Somali refugees. To our knowledge, this is the first study to directly compare two refugee communities who have access to comparable health care services within the same city yet engage in these services differently and suffer different levels of mental illness. Indeed, previous studies have demonstrated language and cultural competencies as major barriers to the utilization of mental health (Salami et al. 2019), but our study indicates that even within communities with these language and cultural challenges there are significant differences in mental illness prevalence and health care access-issues affected by a myriad of factors.

There are many possible explanations for these discrepancies found between the two refugee communities investigated in our study. While the two groups are comparable in many aspects (e.g., average age, marital status), the Somali refugees have been settled in the 
Table 2 Health care access and perceptions of mental health among the study participants

\begin{tabular}{|c|c|c|c|}
\hline Health care access variable & Iraqi $(N=219)$ & Somali $(N=198)$ & $P$ value \\
\hline \multicolumn{4}{|l|}{ Usual venue to seek care when ill } \\
\hline $\begin{array}{l}\text { Doctor's office/private clinic } \\
\text { Community health center/public clinic } \\
\text { Hospital, ER, other / No regular place, don't know }\end{array}$ & $\begin{array}{l}43(19.63) \\
168(76.71) \\
8(3.65)\end{array}$ & $\begin{array}{l}162(81.82) \\
25(12.63) \\
11(5.56)\end{array}$ & $<0.001$ \\
\hline \multicolumn{4}{|l|}{ Regular doctor/nurse/midwife } \\
\hline $\begin{array}{l}\text { Yes } \\
\text { No } \\
\text { Don't know }\end{array}$ & $\begin{array}{l}200(91.32) \\
17(7.76) \\
2(0.91)\end{array}$ & $\begin{array}{l}176(88.89) \\
17(8.59) \\
5(2.53)\end{array}$ & 0.414 \\
\hline \multicolumn{4}{|l|}{ Time in last 12 months when postponed med care } \\
\hline $\begin{array}{l}\text { Yes } \\
\text { No } \\
\text { Don't know }\end{array}$ & $\begin{array}{l}67(30.59) \\
152(69.41) \\
0(0.00)\end{array}$ & $\begin{array}{l}73(36.87) \\
105(53.03) \\
20(10.10)\end{array}$ & $<0.001$ \\
\hline \multicolumn{4}{|l|}{ Of those who postponed med care, it was because of } \\
\hline $\begin{array}{l}\text { Cost } \\
\text { Some other reason } \\
\text { Don't know } \\
\text { Refused }\end{array}$ & $\begin{array}{l}8(11.94) \\
55(82.10) \\
3(4.48) \\
1(1.49)\end{array}$ & $\begin{array}{l}13(17.81) \\
48(65.75) \\
12(16.44) \\
0(0.00)\end{array}$ & 0.046 \\
\hline \multicolumn{4}{|c|}{ Went to a mental health care provider when you needed to } \\
\hline $\begin{array}{l}\text { Yes } \\
\text { No } \\
\text { Did not need to } \\
\text { Refused } \\
\text { Don't know }\end{array}$ & $\begin{array}{l}40(18.26) \\
47(21.15) \\
132(60.27) \\
0(0.00) \\
0(0.00)\end{array}$ & $\begin{array}{l}124(62.63) \\
36(18.18) \\
17(8.59) \\
5(2.53) \\
16(8.08)\end{array}$ & $<0.001$ \\
\hline \multicolumn{4}{|l|}{ Stigma ${ }^{a}$} \\
\hline $\begin{array}{l}\text { No } \\
\text { Yes }\end{array}$ & $\begin{array}{l}39(82.98) \\
8(17.02)\end{array}$ & $\begin{array}{l}35(97.22) \\
1(2.63)\end{array}$ & 0.086 \\
\hline
\end{tabular}

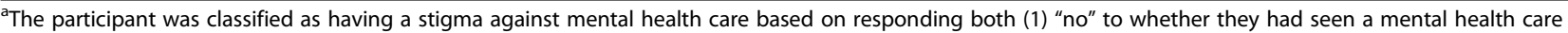
provider when they needed to and (2) the reason for it being: "I was afraid my family would know about it" or "I was afraid my friends, and larger community here would know about it."

USA much longer than Iraqis, possibly enabling longer time to acculturate to life in the USA. This hypothesis is consistent with prior studies suggesting length of time resettled is associated with better assimilation and mental health (Porter and Haslam 2005; Salami et al. 2019), but at odds with others demonstrating longer time in resettlement is associated with worse mental health outcomes (Kirmayer et al. 2011; Uribe Guajardo et al. 2016). Somali respondents felt they had improved social and financial status in the USA compared to their prior country of origin, while Iraqis felt they had a drop in their social status, likely increasing their risk of worse post-migration outcomes. Unfortunately, both populations had a small proportion of respondents who felt they could meet their financial needs "very well". Interestingly, the Somalis spent a longer total period in the transition countries before being resettled, while a greater proportion of Iraqi refugees went to more locations prior to resettlement in the USA. Perhaps the act of relocating more frequently exposes refugees to more factors affecting mental health, such as disruption of social support and networks, trauma, violence, harsh living conditions, and overall uncertainty (Kirmayer et al. 2011). A prior study did show that Somali mothers who

Table 3 Comparison of mental health symptoms between Iraqi and Somali refugee mothers

\begin{tabular}{|c|c|c|c|c|}
\hline & Iraqi $(N=219)$ & Somali $(N=198)$ & Mean difference $(95 \% \mathrm{Cl})$ & $P$ value ${ }^{*}$ \\
\hline HSCL-25 total mean (SD) & $1.71(0.65)$ & $1.37(0.56)$ & $0.34(0.22,0.46)$ & $<0.001$ \\
\hline HSCL-25 depression (Part II) mean (SD) & $1.74(0.62)$ & $1.35(0.56)$ & $0.38(0.27,0.50)$ & $<0.001$ \\
\hline Proportion emotionally distressed, no (\%) ${ }^{\mathrm{a}}$ & $75(34.56)$ & $38(19.19)$ & - & $<0.001$ \\
\hline Proportion with major depression, no $(\%)^{\mathrm{b}}$ & $132(60.83)$ & $53(26.77)$ & - & $<0.001$ \\
\hline
\end{tabular}

Higher scores indicate worse mental health symptoms

Abbreviations: HSCL-25 Hopkins Symptoms Checklist-25, Cl confidence interval, SD standard deviation

${ }^{a}$ 'Emotionally distressed' was classified as total score $>1.75$

' ${ }^{\prime}$ Major depression' was classified as an average score of $>1.45$ on the depression section (HSCL-25 Part II)

"Two-tailed $P$ value calculated by independent samples $t$ test for continuous variables (HSCL-25 scores) and chi-squared tests for proportions of distressed respondents 
Table 4 Multivariable logistic regression results for predictors of depression and emotional distress

\begin{tabular}{|c|c|c|c|c|}
\hline \multirow[t]{2}{*}{ Variable } & \multicolumn{2}{|l|}{ Major depression } & \multicolumn{2}{|l|}{ Emotional distress } \\
\hline & OR & $P$ value & OR & $P$ value \\
\hline \multicolumn{5}{|l|}{ Country of origin } \\
\hline Somali & Ref. & & Ref. & \\
\hline Iraqi & $2.62(1.50-4.57)$ & 0.001 & $1.42(0.78-2.57)$ & 0.249 \\
\hline Age (years) & $1.03(1.00-1.07)$ & 0.076 & $1.03(0.99-1.07)$ & 0.168 \\
\hline \multicolumn{5}{|c|}{ Access to mental health provider in the USA } \\
\hline $\begin{array}{l}\text { No } \\
\text { Yes } \\
\text { Did not need to see } \\
\text { Don't know } \\
\text { Refused to answer }\end{array}$ & $\begin{array}{l}\text { Ref. } \\
\mathbf{0 . 4 2}(\mathbf{0 . 2 2}-\mathbf{0 . 8 2}) \\
0.57(0.32-1.02)\end{array}$ & $\begin{array}{l}\mathbf{0 . 0 1 1} \\
0.058\end{array}$ & $\begin{array}{l}\text { Ref. } \\
0.43(0.22-0.85) \\
0.47(0.26-0.87)\end{array}$ & $\begin{array}{l}0.015 \\
0.016\end{array}$ \\
\hline \multicolumn{5}{|l|}{ Prior psychiatric diagnosis } \\
\hline No & Ref. & & Ref. & \\
\hline Yes & $10.97(3.80-31.71)$ & $<0.001$ & $6.46(2.87-14.58)$ & $<0.001$ \\
\hline
\end{tabular}

Covariables were included in the multivariable analysis if significant on univariable analysis at alpha level $P<0.05$, except for time awaiting resettlement and time in resettlement in the USA given the relatively high rate of missing data amongst these variables $\left(n_{\text {missing }}=297,71.22 \%\right.$ and $n_{\text {missing }}=124,29.74 \%$, respectively) that would introduce instability into the multivariable model

Abbreviations: OR odds ratio

had a history of trauma and torture were significantly more likely to suffer from depression and PTSD (East et al. 2018). Indeed, the association between trauma exposure and mental illness has been well documented (Steel et al. 2009), suggesting that this relationship would hold true for the Iraqi population in question.

Although Iraqi refugees were more educated, they still had a stigma against utilizing mental health care services in San Diego. Prior work has discussed how stigma associated with mental health disease in Iraq seems to be greater than in other parts of the world, and this stigma leads to reluctance to engage with treatment (Bolton 2013). Among the Iraqi refugee community, those who speak out about mental health can be considered 'crazy'. Even if patients do want to seek care, they may not trust the health professionals and, particularly among women, they may be unable to seek care without family consent or a male chaperone to leave the home (Sadik et al. 2010). These barriers to care are concerning, especially since our study showed that refugees who had seen a mental health provider when needed had more favorable HSCL scores. Given this is a cross-sectional study, we cannot ascertain whether those who sought health care were less likely to be depressed because of the care they received or because their psychiatric disease was milder in the first place. Future studies optimally designed to investigate this question are needed.

The type of health care services also differed between the two populations. Somalis utilized a clinic setting whereas Iraqis utilized community-based services. This discrepancy can largely be attributed to the geographic location of Iraqis in El Cajon, an area of San Diego rich in community clinics, in addition to the Iraqi community's dependence on refugee-specific services. Alternatively, Somalis are more established and live in a different location that does not have as high of a proportion of community clinics; thus, they have likely sought out additional health services beyond those only serving refugee communities. This finding might also reflect health insurance preferences by the two populations.

This study highlights an interesting difference in mental health utilization between the two groups, specifically that most Iraqis had not seen a mental health provider in the past year (as opposed to most Somalis who had sought care). Given Iraqis had worse mental health outcomes overall, this differential use of mental health services likely suggests that there is a large proportion of the Iraqi population who could benefit from seeing a mental health provider. Interestingly, most Iraqis who answered that they did not see a mental health provider reported that this was because they did not need to, revealing what is likely a misconception, denial, or fear of disclosing mental health illness among the Iraqi community. This discrepancy illuminates an opportunity to improve mental health education and care for the Iraqi refugee community, which prior research on resettled Iraqi refugees has shown can be accomplished through better provider knowledge of the Iraqi culture and community, effective communication, understanding of traditional beliefs, and backgrounds behind negative attitudes toward mental health disease (Guajardo et al. 2016). Surprisingly, Somalis reported more negative perceptions of health care providers, but still were more likely to utilize mental health services and demonstrated better mental health outcomes. One possible explanation is that providers may have implicit bias impacted by 
patient appearance and affecting how they interact with their patients, given most Iraqis (81\%) were Christians who do not wear culturally identifying clothes as opposed to the Muslim Somalis (99.5\%) who mostly wear hijabs (i.e., traditional Muslim headscarves). Or perhaps this negative perception of providers among Somalis could be related to their lower education status and/or language barriers. Racism may also have played a role given that Somalis generally have a darker complexion, as opposed to Iraqis.

Both groups, but particularly the Iraqis, had an inverse association between those who met criteria for major depression and those who actually saw a mental health provider. This could be perceived as evidence that interaction with mental health services has had a beneficial effect on respondent's mental health. However, the fact that participants with higher levels of mental health were less likely to see a provider highlights an unmet need. To provide appropriate mental health services for these populations, we need new and culturally appropriate approaches. It is, however, encouraging that the few who are utilizing mental health services demonstrate a decreased likelihood of depression or emotional distress. Based on these results, more work is needed to identify barriers to accessing mental health care among refugees who would otherwise benefit from these services.

This study has some limitations. First, the crosssectional study design precludes any assessments of causality or temporality-specifically we cannot ascertain whether participants accessed mental health before or after their diagnosis of a mental illness. However, given the chronic nature of depression and the fact that the disease is commonly precipitated by trauma (East et al. 2018), it is highly likely that mental illnesses were present before seeking mental health care clinic. This study also focused on refugee mothers specifically as opposed to fathers or other caregivers, so we cannot generalize our findings to men in the Iraqi and Somali refugee communities. Compared to women, men are generally less likely to admit to illnesses, especially mental illnesses (The World Health Report 2001). There were differences in the methods of data collection between the two study samples: the Iraqi population was sampled at random, while the Somali population was a convenient sample recruited by door-to-door search for qualified mothers. The Somali study group may therefore be a biased sample of unemployed or lower paid people given the community tends to congregate in City Heights and in certain apartment complexes until they get higher paying jobs elsewhere. Furthermore, missing data precluded the inclusion of time awaiting resettlement and time in resettlement in the USA in the multivariable analysis. Given significant differences between the two groups with regard to these measures, it should be noted that the results may have been confounded by this omission.

While the HSCL-25 has been shown to be useful in non-western refugee patients, prior investigations have varied in the robustness of using the standard cutoffs in Iraqi and Somali patients (Wind et al. 2017; Weiss 2015; Taylor et al 2014). Further work is needed to validate using these cutoffs (i.e., average total score $>1.75$ or depression score $>1.45$ ) to define psychiatric illness for the purposes of comparing two different populations, which is why in this study we also included results of HSCL-25 scores as a continuous variable. Lastly, there may be different interpretations of the word "disease" that varies by individual and possibly non-randomly between the two groups. Therefore, admission of having a "psychiatric disease" on the survey may depend on one's impression of the implication of the word.

\section{Conclusion}

This study suggests that access to mental health services was associated with decreased odds of depression and emotional distress among refugee mothers in San Diego. However, despite relatively uniform services available to refugees in this city, Iraqi refugees were more likely to be depressed compared to Somalis. For the first time, we report that even within the same city, the cultural background of the refugee community impacts the utilization of health care. These results also highlight the potential for a myriad of factors that could have a crucial impact on access to mental health services. Service providers should work to identify these factors in order to reduce barriers to refugee service utilization. It is concerning that both populations often do not utilize mental health care resources, even if they were currently suffering from emotional distress or depression. Mental health care is a more sensitive discipline with complex cultural and stigma barriers and requires much more trust and understanding when compared to other health related resources. A better understanding of the risk factors and obstacles to seeking care requires further investigation to improve upon culturally specific means of providing mental health care to relocated refugees.

\section{Supplementary Information}

The online version contains supplementary material available at https://doi. org/10.1186/s41018-020-00081-5.

Additional file 1: Table S1. Comfort with health care provider by refugee population.

\section{Acknowledgements}

The authors have no acknowledgments to make.

Authors' contributions

WB and KT were responsible for the development and implementation of the methods and preparation of the manuscript and statistical analyses. WA 
was responsible for all of the aforementioned roles in addition to data collection. The authors read and approved the final manuscript.

\section{Funding}

There are no funding sources to disclose.

\section{Availability of data and materials}

Data sets are available upon request.

\section{Ethics approval and consent to participate}

The University of California San Diego Human Research Protections Program conducted an ethical review and approved the study. The study reference number is 111857 .

\section{Competing interests}

The authors have no conflicts of interest to report.

\section{Author details}

'Department of Emergency Medicine, Keck School of Medicine, University of Southern California, 1200 N State Street, Room 1011, Los Angeles, CA 90033. USA. ${ }^{2}$ Department of Radiation Oncology, Memorial Sloan Kettering Cancer Center, New York, NY, USA. ${ }^{3}$ Department of Family Medicine and Public Health, University of California at San Diego School of Medicine, San Diego, CA, USA.

\section{Received: 25 November 2019 Accepted: 25 October 2020}

\section{Published online: 09 November 2020}

\section{References}

Admissions \& arrivals — refugee processing center (2020) Retrieved 20 Nov 2018 from http://www.wrapsnet.org/admissions-and-arrivals/

Al-Nuaimi MA, Hamad RA, Lafta RK (2015) Effects of witnessing or exposure to community violence on mental health of Iraqi men. Qatar Medical Journal 2015(1):10. https://doi.org/10.5339/qmj.2015.10

Bhui K, Abdi A, Abdi M, Pereira S, Dualeh M, Robertson D et al (2003) Traumatic events, migration characteristics and psychiatric symptoms among Somali refugees. Social Psychiatry and Psychiatric Epidemiology 38(1):35-43. https:// doi.org/10.1007/s00127-003-0596-5

Bolton P (2013) Mental health in Iraq: issues and challenges. The Lancet 381(9870):879-881

Chkam H (2016) Aid and the perpetuation of refugee camps: the case of Dadaab in Kenya 1991-2011. Refugee Survey Quarterly 35(2):79-97. https://doi.org/10. 1093/rsq/hdw005

Dadaab refugee complex - UNHCR Kenya. Retrieved 22 Nov 2018, from https:// www.unhcr.org/ke/dadaab-refugee-complex

Dennis CL, Chung-Lee L (2006) Postpartum depression help-seeking barriers and maternal treatment preferences: a qualitative systematic review. Birth. https:// doi.org/10.1111/j.1523-536X.2006.00130.X

Derogatis LR, Lipman RS, Rickels K, Uhlenhuth EH, Covi L (1974) The Hopkins Symptom Checklist (HSCL): a self-report symptom inventory. Behavioral Science 19(1):1-15 Retrieved from http://www.ncbi.nlm.nih.gov/pubmed/4808738

East PL, Gahagan S, Al-Delaimy WK (2018) The impact of refugee mothers' trauma, posttraumatic stress, and depression on their children's adjustment. Journal of Immigrant and Minority Health 20(2):271-282. https://doi.org/10. 1007/s10903-017-0624-2

Fazel M, Wheeler J, Danesh J (2005) Prevalence of serious mental disorder in 7000 refugees resettled in western countries: a systematic review. The Lancet 365(9467):1309-1314 10.1016/S0140-6736(05)61027-6

Guajardo M, Slewa-Younan S, Santalucia Y, Jorm A (2016) Important considerations when providing mental health first aid to Iraqi refugees in Australia: a Delphi study. Int J Ment Health Syst 10(1):54

Hess JM, Isakson B, Nelson M, Goodkind JR. "My World Is Upside Down": Transnational Iraqi Youth and Parent Perspectives on Resettlement in the United States. J Immigr Refug Stud. 2018;16(4):391-412. https://doi.org/10. 1080/15562948.2017.1338367.

Jamil H, Farrag M, Hakim-Larson J, Kafaji T, Abdulkhaleq H, Hammad A (2007) Mental health symptoms in Iraqi refugees: posttraumatic stress disorder, anxiety, and depression. Journal of Cultural Diversity 14(1):19-25 Retrieved from http://www.ncbi.nlm.nih.gov/pubmed/19172969

Jaranson JM, Butcher J, Halcon L, Johnson DR, Robertson C, Savik K et al (2004) Somali and Oromo refugees: correlates of torture and trauma history.
American Journal of Public Health 94(4):591-598 Retrieved from http://www. ncbi.nlm.nih.gov/pubmed/15054011

Kirmayer L, Narasiah L, Munoz M, Rashid M, Ryder AG, Guzder J et al (2011) Common mental health problems in immigrants and refugees: general approach in primary care. CMAJ 183(12):E959-E967. https://doi.org/10.1503/cmaj.090292

Leone S (1983) Total refugee arrivals to California by country of origin federal fiscal. Retrieved from https://www.cdss.ca.gov/Portals/9/Refugee/Arrivals/ Total_Arrivals_Country_of_Origin_by_Year_1983-2017.pdf?ver=201805-23-155445-873

Lopez-Villafana A. Language, cultural barriers limit San Diego Somali residents access to COVID-19 resources - The San Diego Union-Tribune. The San Diego Union-Tribune. 2020 https://www.sandiegouniontribune.com/communities/ san-diego/story/2020-04-19/san-diego-somali-community-amongvulnerableduring-pandemic. Accessed 3 Aug 2020.

Matsuoka J (1993) Demographic characteristics as determinants in qualitative differences in the adjustment of vietnamese refugees. Journal of Social Service Research 17(3-4):1-21. https://doi.org/10.1300/J079v17n03 01

Murray KE, Davidson GR, Schweitzer RD (2010) Review of refugee mental health interventions following resettlement: best practices and recommendations. The American Journal of Orthopsychiatry 80(4):576-585. https://doi.org/10. 1111/j.1939-0025.2010.01062.x

Polonsky JA, Ronsse A, Ciglenecki I, Rull M, Porten K (2013) High levels of mortality, malnutrition, and measles, among recently-displaced Somali refugees in Dagahaley camp, Dadaab refugee camp complex, Kenya, 2011. Conflict and Health 7(1):1. https://doi.org/10.1186/1752-1505-7-1

Porter M, Haslam N (2005) Predisplacement and postdisplacement factors associated with mental health of refugees and internally displaced persons. JAMA 294(5):602. https://doi.org/10.1001/jama.294.5.602

Rometsch-Ogioun El Sount C, Denkinger JK, Windthorst P, Nikendei C, Kindermann D, Renner $V$ et al (2018) Psychological burden in female, Iraqi refugees who suffered extreme violence by the "Islamic State": the perspective of care providers. Frontiers in Psychiatry 9:562. https://doi.org/10.3389/fpsyt.2018.00562

Sadik S, Bradley M, Al-Hasoon S, Jenkins R (2010) Public perception of mental health in Iraq. Int J Ment Health Syst 4:26

Salami B, Salma J, Hegadoren K (2019) Access and utilization of mental health services for immigrants and refugees: perspectives of immigrant service providers. International Journal of Mental Health Nursing 28(1):152-161. https://doi.org/10.1111/inm.12512

Silove D, Ventevogel P, Rees S (2017) The contemporary refugee crisis: an overview of mental health challenges. World Psychiatry 16(2):130-139. https://doi.org/10.1002/wps.20438

Steel Z, Chey T, Silove D, Marnane C, Bryant RA, Van Ommeren M (2009) Association of torture and other potentially traumatic events with mental health outcomes among populations exposed to mass conflict and displacement: a systematic review and meta-analysis. JAMA. https://doi.org/10.1001/jama.2009.1132

Steward D, Gagnon A, Saucier J, Wahoush O, Dougherty G (2008) Postpartum depression symptoms in newcomers. Can J Psychiatr 53(2)

Syed HR, Zachrisson HD, Dalgard OS, Dalen I, Ahlberg N (2008) Concordance between Hopkins Symptom Checklist (HSCL-10) and Pakistan Anxiety and Depression Questionnaire (PADQ), in a rural self-motivated population in Pakistan. BMC Psychiatry 8:59. https://doi.org/10.1186/1471-244X-8-59

Takeuchi DT, Zane N, Hong S, Chae DH, Gong F, Gee GC et al (2007) Immigration-related factors and mental disorder among Asian Americans. American Journal of Public Health. https://doi.org/10.2105/AJPH.2006.088401

Taylor EM, Yanni EA, Pezzi C, et al. Physical and Mental Health Status of Iraqi Refugees Resettled in the United States. J Immigr Minor Heal. 2014;16(6): 1130-1137. https://doi.org/10.1007/s10903-013-9893-6.

Terrazas A (2009) Iraqi immigrants in the United States | migrationpolicy.org. Retrieved 20 Nov 2018, from https://www.migrationpolicy.org/article/iraqiimmigrants-united-states

The World Health Report (2001) Mental health: new understanding, new hope. WHO, Geneva

UNHCR (2016) UNHCR's global trends - forced displacement in 2016. Retrieved 15 Dec 2018. https://www.unhcr.org/en-us/statistics/unhcrstats/5943e8a34/ global-trends-forced-displacement-2016.html

UNHCR (2018) Resettlement. Retrieved 22 Dec 2018, from https://www.unhcr.org/ resettlement.html

UNHCR UNHCR's mental health and psychosocial support for persons of concern. Global Review 2013. Accessed 20 Dec 2018. https://www.unhcr.org/en-us/ research/evalreports/51 bec3359/unhcrs-mental-health-psychosocial-supportpersons-concern.htm 
Uribe Guajardo MG, Slewa-Younan S, Smith M, Eagar S, Stone G (2016) Psychological distress is influenced by length of stay in resettled Iraqi refugees in Australia. International Journal of Mental Health Systems 10(1):4 https://doi.org/10.1186/s13033-016-0036-z

Weiss WM, Murray LK, Zangana GAS, et al. Community-based mental health treatments for survivors of torture and militant attacks in Southern Iraq: A randomized control trial. BMC Psychiatry. 2015;15(1):1-16. https://doi.org/10. 1186/s12888-015-0622-7.

WHO (2012) WHO urges more investments, services for mental health. WHO, Geneva Retrieved from http:/www.who.int/mental_health/who_urges_investment/en/ Wind TR, van der Aa N, de la Rie S, Knipscheer J (2017) The assessment of psychopathology among traumatized refugees: measurement invariance of the Harvard Trauma Questionnaire and the Hopkins Symptom Checklist-25 across five linguistic groups. European Journal of Psychotraumatology. https://doi.org/10.1080/20008198.2017.1321357

\section{Publisher's Note}

Springer Nature remains neutral with regard to jurisdictional claims in published maps and institutional affiliations.

\section{Submit your manuscript to a SpringerOpen ${ }^{\odot}$ journal and benefit from:}

- Convenient online submission

- Rigorous peer review

- Open access: articles freely available online

- High visibility within the field

- Retaining the copyright to your article

Submit your next manuscript at $\boldsymbol{\wedge}$ springeropen.com 